\title{
A Comparative Study of Features of Sorption of N-Buthylxanthate and Dibuthyldixanthogen Onto Metallic Supports and Rutile Using in situ Atomic Force Spectroscopy
}

\author{
Anton A. Karacharov* and Maxim N. Likhatski \\ Institute of Chemistry and Chemical Technology SB RAS \\ FRC "Krasnoyarsk Science Center SB RAS" \\ 50/24 Akademgorodok, Krasnoyarsk, 660036, Russia
}

Received 13.02.2019, received in revised form 12.04.2019, accepted 26.08.2019

\begin{abstract}
An interaction of potassium buthylxanthate and of dibuthyldixanthogen with metallic Ti, stainless steel and $\alpha-\mathrm{TiO}_{2}$ surfaces was studied. Contact angle measurements by sessile drop technique showed that the treatment of initial substrate surfaces with potassium buthylxanthate aqueous solution or with dibuthyldixanthogen emulsion render them more hydrophobic. Using in situ atomic force spectroscopy, the sorption of surface active substances was shown to give rise to an increase in both adhesive force magnitude and the range within it acts at the approach of cantilever tip to the surface of both hydrophobic and hydrophilic samples. The maximum of both adhesive force and their range, up to 150 $\mathrm{nm}$, took place in case of retract of cantilever tip from sample surface. Force curves are steeper, which related with the formation of nanobubbles on the surfaces of samples under study arising the longrange hydrophobic force of capillary origin. Dibuthyldixanthogen exhibited highly-active reagent properties inducing the formation of nanoscale gas structures on both hydrophobic and, in less extent, hydrophilic surfaces.
\end{abstract}

Keywords: nanobubbles, surface, hydrophobic, sorption, potassium buthylxanthate, dibuthyldixanthogen, atomic force spectroscopy, contact angle.

Citation: Karacharov A.A., Likhatski M.N. A comparative study of features of sorption of n-buthylxanthate and dibuthyldixanthogen onto metallic supports and rutile using in situ atomic force spectroscopy, J. Sib. Fed. Univ. Chem., 2019, 12(3), 336-346. DOI: 10.17516/1998-2836-0131.

(C) Siberian Federal University. All rights reserved

* Corresponding author E-mail address: AntonKaracharov@ya.ru 


\title{
Сравнительное исследование особенностей сорбции
}

\author{
н-бутилксантогената и дибутилдиксантогена
}

на металлические подложки и рутил

с применением in situ атомно-силовой спектроскопии

\author{
А.А. Карачаров, М.Н. Лихацкий \\ Институт химии и химической технологии СО РАН \\ ФИЦ «Красноярский научный центр СО РАН» \\ Россия, 660036, Красноярск, Академгородок, 50/24
}

Изучено взаимодействие н-бутилксантогената калия и дибутилдиксантогенида с поверхностями ряда субстратов титана, нержавеющей стали и рутила ( $\left.\alpha-\mathrm{TiO}_{2}\right)$. Измерение величины краевого угла смачивания методом сидячей капли показало, что обработка исходных поверхностей образцов растворами бутилксантогената калия и эмульсией дибутилдиксантогена приводит к увеличению их гидрофобности. Методом атомно-силовой спектроскопии іп situ было показано, что действие ПАВ вызывает увеличение силы притяжения и диапазон ее действия при подводе игльк кантилевера к поверхности как гидрофобных, так и гидрофильных образцов. Наибольшая величина сил притяжения и их дальнодействия до 150 нм обнаруживается при отводе игльл кантилевера от поверхности образиов. Силовые кривые имеют характерный ступенчатый вид, обусловленный образованием на поверхности образиов нанопузырьков, вызывающих появление дальнодействующих гидрофобных сил притяжения капиллярной природы. Дибутилдиксантоген проявил себя как высокоактивный реагент, вызылвающий образование наноразмерных газовых структур на гидрофобных и, в меньшей степени, на гидрофильных поверхностях.

Ключевые слова: нанопузырьки, гидрофобность, сорбция, н-бутиксантогенат калия, дибутилдиксантоген, атомно-силовая микроскопия, краевой угол смачивания.

\section{Введение}

Среди поверхностных сил гидрофобное притяжение является одним из наиболее важных неспецифических взаимодействий. Они играют ключевую роль как в биологических (самоупорядочение белковых молекул и мембран и т.п.), так и технологических (флотационное разделение руд и минералов, антиобледенительная и антикоррозионная защита конструкционных материалов и др.) системах. Авторы [1] более 35 лет назад впервые провели непосредственное измерение сил гидрофобного притяжения на приборе для измерения поверхностных сил (Surface Force Apparatus (SFA)) и установили, что они на порядок величины превосходят силы вандерваальсового взаимодействия. В дальнейшем силы гидрофобного взаимодействия стали объектом целого ряда исследований, выполненных на приборе SFA, позднее - с помощью метода атомно-силовой микроскопии (ACM) и спектроскопии (ACC). В результате было открыто 
исключительное дальнодействие сил гидрофобного взаимодействия, достигающее сотен нанометров [1-4].

В литературе для объяснения сил гидрофобного взаимодействия был предложен целый ряд механизмов и моделей, включающих: а) энтропийное происхождение, обусловленное конформационным переупорядочением соседних молекул воды в пространстве между гидрофобными поверхностями $[1,8,9]$; б) капиллярные силы, проявляющиеся за счет образования мостиков из поверхностных нанопузырьков [10, 11]; в) воздушные полости, образование которых рассматривается как фазовый переход, вызванный разделением гидрофобных поверхностей друг от друга [12-14]; г) корреляцию гидродинамических флуктуаций [15]; д) действие электростатической силы [16]; е) корреляцию флуктуаций поверхностного заряда [17].

В настоящее время образование поверхностных нанопузырьков, по мнению большинства исследователей, рассматривается в качестве основной причины проявления дальнодействия при взаимодействии гидрофобных поверхностей. Хотя первое предположение о существовании поверхностных газовых пузырьков на гидрофобных поверхностях было высказано еще в середине 1990-х годов [10], первое АСМ изображение нанопузырьков было опубликовано в 2000 году $[18,19]$. На сегодня существование, широкое распространение и основные свойства газовых наноструктур доказаны и изучены и другими методами.

Недавно с помощью измерений методами АCM/ACС в воде нами было установлено, что обработка галенита $(\mathrm{PbS})$ и высокоориентированного пиролитического графита (ВОПГ) растворами н-бутилксантогената калия приводит к появлению на их поверхности наноразмерных газовых пузырьков [20]. Возникающие дальнодействующие гидрофобные силы притяжения препятствовали отрыву зонда, а также пузырька воздуха от таких поверхностей. Было высказано предположение, что именно незначительные количества диксантогената, образующиеся на поверхности галенита или осаждающиеся из объема раствора, способствуют формированию поверхностных газовых структур [20].

Дальнейшие исследования влияния обработки микроэмульсий дибутилксантогената на свойства гидрофобной (ВОПГ) и гидрофильной $\left(\mathrm{SiO}_{2}\right)$ поверхностей, проведенные методом $\mathrm{ACC}$ с коллоидным зондом (микросфера $\mathrm{SiO}_{2}$ ), подтвердили данную гипотезу [21]. На полученных в работе [21] АСС кривых наблюдали возникновение дальнодействующих капиллярных сил притяжения большой амплитуды между зондом и подложкой в воде. Наблюдаемое взаимодействие было значительно сильнее при отводе коллоидного зонда, чем при приближении, и на ВОПГ, чем на $\mathrm{SiO}_{2}$. При этом влияние диксантогена проявляется при значительно меньших по сравнению с бутилксантогенатом калия, примерно в 10 раз, временах экспозиции даже на поверхности $\mathrm{SiO}_{2}$. Таким образом, дибутилдиксантоген проявляет свойства высокоактивного гидрофобизирующего реагента.

В настоящей работе было проведено исследование влияния водных микроэмульсий дибутилдиксантогена в сравнении с действием растворов н-дибутилдиксантогена калия на гидрофобные свойства поверхностей $\mathrm{Ti}, \mathrm{Fe}$ (слабогидрофобные) и $\mathrm{TiO}_{2}, \mathrm{SiO}_{2}$ (гидрофильные). В работе применили in situ методы атомно-силовой микроскопии (ACM) и спектроскопии (ACC). Гидрофильно-гидрофобные свойства исследуемых поверхностей оценивали также ex situ путем измерения величины краевого угла смачивания методом сидячей капли. 


\section{Экспериментальная часть}

Реактивы. В работе использовали очищенный перекристаллизацией из ацетона промышленный н-бутилксантогенат калия (KBX). Синтез водных эмульсий дибутилдиксантогената $\left((\mathrm{BX})_{2}\right)$ проводили окислением н-бутилксантогената калия элементным йодом в водном растворе. Образующийся диксантоген отделяли от маточного раствора и промывали декантацией. Для получения суспензии 2 мкл диксантогена редиспергировали с помощью ультразвука в 100 мл $\mathrm{H}_{2} \mathrm{O}$ [21]. Все остальные реактивы, использованные в работе, были не ниже класса ч.д.а.

В качестве субстратов в работе были применены ВОПГ (НТ-МДТ, Москва), металлические пластины титана и нержавеющей стали $(08 \mathrm{X} 18 \mathrm{H} 10 \mathrm{~T})$ размером 0,7x0,7 см. Поверхность металлических пластин полировали на дисках из древесины березы с пастой из синтетических алмазов с размером зерен 1 и 0,5 мкм. Гидрофильный слой $\alpha-\mathrm{TiO}_{2}$ (рутила) получали согласно методике [22], путем электрохимического окисления шлифованной стороны Ті пластины в 0,5 моль/л растворе $\mathrm{H}_{2} \mathrm{SO}_{4}$ при 9 В в течение 30 мин.

Поверхность субстратов очищали от загрязнений перед каждым экспериментом, промывая последовательно гексаном, ацетоном, этиловым спиртом и деионизованной водой.

Исследования методом атомно-силовой спектроскопии (АCC) и микроскопии (АСM) проводили с использованием сканирующего зондового микроскопа Solver P47 (НТ-МДТ, Москва), оснащенного 14 мкм сканером, в открытой титановой жидкостной ячейке. Образцы для АCC/ АCМ-измерений готовили, погружая пластины либо в 0,1 ммоль/л водный раствор КВХ на 10 мин, либо в эмульсию диксантогена на 1 мин, затем ополаскивали водой и переносили в ячейку с деионизованной водой. В АСС-исследованиях использовали кремниевые прямоугольные зонды CSG 30 (НT-МДТ, Москва) с силовой константой 0,06 H/M² и радиусом кривизны иглы менее 10 нм. Актуальную величину константы жесткости кантилевера определяли in situ методом термальных колебаний (thermalmethod) [23] с помощью модуля, встроенного в программное обеспечение микроскопа (Nova 9.2.6). Скорость подвода во всех экспериментах была равна 1 мкм/мин. Получаемые силовые кривые в виде зависимости сигнала DFL, пропорционального вертикальному изгибу кантилевера, от величины выдвижения пьезосканера $(\Delta \mathrm{Z})$ были конвертированы в программе SPIP 6.4 (Image Metrology) с получением зависимости силы взаимодействия (нН/ ${ }^{2}$ ) от расстояния зонд-образец. Для получения изображений АCM в полуконтактной моде использовали прямоугольные кантилеверы NSG 30, типичная силовая константа 6 H/м, резонансная частота в жидкости 110 кГц, радиус кривизны иглы около 10 нм.

Измерение краевых углов смачивания проводили методом сидячей капли при комнатной температуре с использованием автоматизированного оптического анализатора ОСА 15EC с температурным датчиком TDC-160 (DataPhysics, Германия). Объем капель деионизированной воды во всех экспериментах был фиксирован и равен 5 мкл, скорость дозирования составляла 1 мкл/с. Для каждого образца проводили как минимум пять параллельных измерений в пяти различных областях на исследуемой поверхности. Данная процедура позволяла минимизировать искажения, вносимые в величину краевого угла смачивания, в связи с возможной неоднородностью поверхности образцов. Получаемые с помощью встроенной камеры изображения профиля капель анализировались с помощью программного пакета SCA (Version 5.0.12 Build 5012).

$$
-339-
$$




\section{Результаты}

На рис. 1 приведены результаты измерения краевых углов смачивания для нержавеющей стали, $\mathrm{Ti}, \mathrm{TiO}_{2}$ до и после их контакта с растворами ПАВ. Измерения краевых углов проводили методом сидячей капли.

Как видно из представленных данных, исходные поверхности металлов имеют слабо выраженные гидрофобные свойства, а $\mathrm{TiO}_{2}$ - гидрофильные. Сорбция бутилксантогената калия в течение 10 мин приводит к росту величины краевого угла смачивания у всех исследуемых образцов, и в наибольшей степени для нержавеющей стали, на $13,8^{\circ}$.

Предварительная обработка субстратов эмульсией дибутилдиксантогена в течение 60 с вызывает рост краевого угла смачивания на титане и нержавеющей стали примерно на ту же величину, что и бутилксантогенат калия (KBX). В случае $\mathrm{TiO}_{2}$ сорбция диксантогена приводит, наоборот, к незначительному росту гидрофильности поверхности образца, уменьшая значение краевого угла смачивания примерно на $3^{\circ}$. Данное явление может быть связано с тем, что дибутилдиксантоген, сорбируясь на поверхности $\mathrm{TiO}_{2}$, не образует сплошной пленки, а формирует субмикронные и/или наноразмерные капли, увеличивая тем самым исходную неоднородность поверхности. Согласно работе [24], рост неоднородности гидрофильной поверхности уменьшает величину краевого угла смачивания. Стоит отметить, что метод оценки гидрофильно-гидрофобных свойств по величине краевого угла смачивания отражает лишь усредненные макроскопические свойства

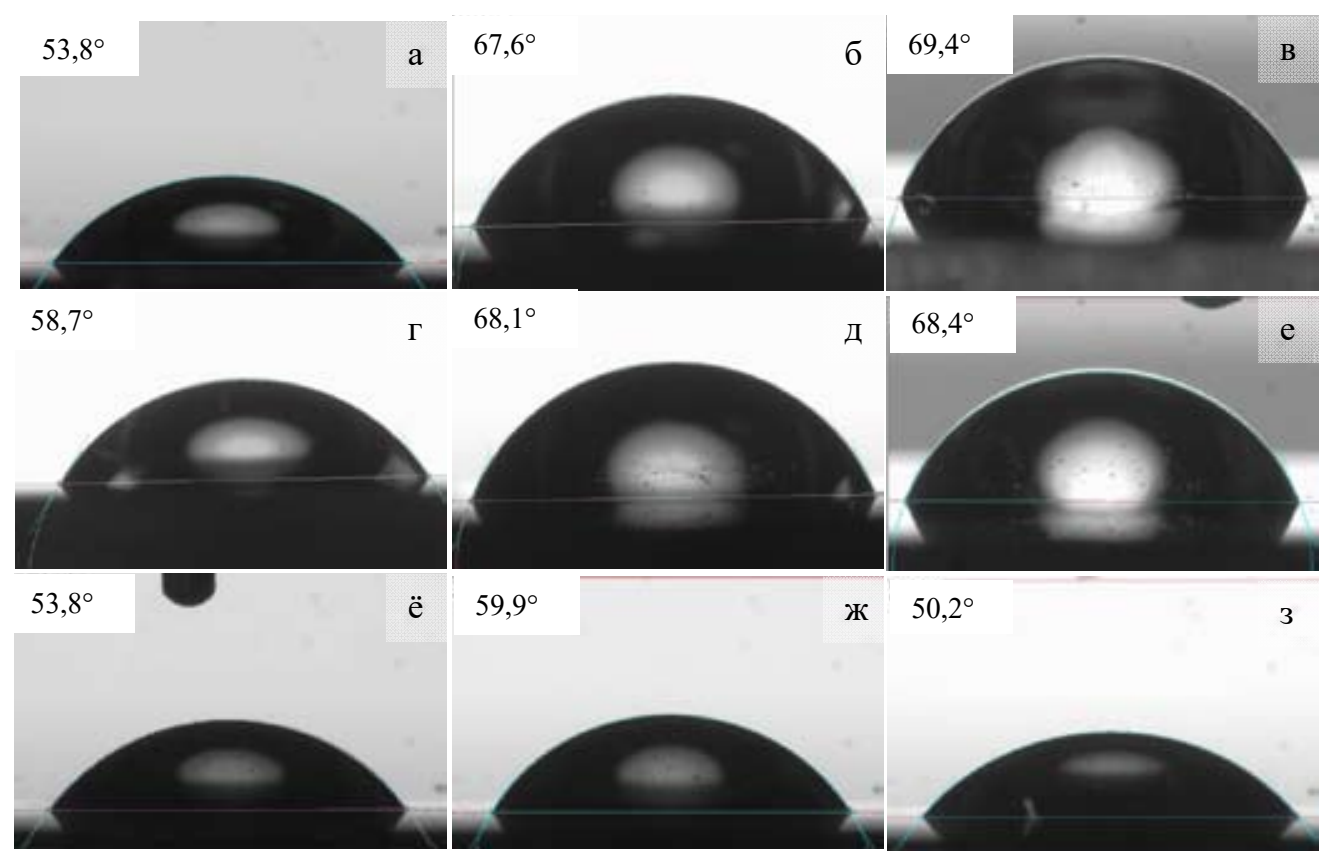

Рис. 1. Характерные изображения капли деионизованной воды на поверхности (а-в) нержавеющей стали, (г-е) металлического титана, (ё-з) рутила до (а, г, ё) и после кондиционирования в 10 мМ растворе н-бутилксантогената в течение 10 мин (б, д, ж) либо в эмульсии диксантогена в течение 1 мин (в, е, з)

Fig. 1. Typical images of deionized water drop on stainless steel plate (a-в), metallic $\mathrm{Ti}(\Gamma-\mathrm{e})$ and $\alpha-\mathrm{TiO}_{2}(\ddot{\mathrm{e}}-3)$, before $(\mathrm{a}, \Gamma, \ddot{\mathrm{e}})$ and after conditioning in $10 \mathrm{mM}$ potassium $\mathrm{n}$-bythylxanthate solution for $10 \mathrm{~min}(б$, д, ж), or in dibythyldixanthogen emulsion for $1 \mathrm{~min}(\mathrm{в}, \mathrm{e}, 3)$ along with corresponding averaged contact angle values 
поверхностей. Для оценки поверхностных гидрофобных дальнодействующих сил притяжения на нано- и субмикронном уровнях нами были применены in situ методы АCM и ACC.

В силу высокой адгезии дибутилдиксантогена к твердым поверхностям время контакта подложек $\left(\mathrm{Ti}, \mathrm{Fe}, \mathrm{TiO}_{2}\right)$ с микроэмульсиями было ограничено, как правило, 1 мин. Более длительный контакт не позволяет осуществить процедуру подвода зонда к поверхности образца, возможно, из-за образования больших капель диксантогена и/или поверхностных газовых структур. В случае раствора н-бутилксантогената калия время сорбции составляло 10 мин.

После обработки подложек растворами ПАВ надежно обнаружить поверхностные продукты взаимодействия с помощью in situ полуконтактной АCM не удается. Это может указывать на удаление части капель дибутилдиксантогена в процессе промыва образцов или образования тонкой, до нескольких молекулярных слоев, однородной пленки. Кроме того, на АСМизображениях наблюдали признаки взаимодействия зонда с поверхностными наноразмерными структурами, приводившего, как кажется, к их смещению или частичному удалению с поверхности образца. В случае $\mathrm{TiO}_{2}$ этому мешала также субмикронная неоднородность (шероховатость около 60 нм) исходной поверхности субстратов, на фоне которой сложно было выделить вклад от нанопузырьков и/или капель диксантогена.

Характерные зависимости силы взаимодействия иглы кантилевера от расстояния в воде до и после их взаимодействия с растворами ПАВ представлены на рис. 2.

В случае исходных поверхностей при подводе на АСС кривых обнаруживается небольшое притяжение, видимо, электростатической природы. При отводе наблюдается один скачок за счет упругости кантилевера; сила взаимодействия достигает нулевого значения на расстоянии от поверхности чуть более 15 нм.

После десятиминутного контакта металлов с 10 мМ раствором бутилксантогената калия при подводе возникают значительные силы притяжения, а скачок зонда в контакт наблюдается на большем расстоянии, примерно 25 нм. Силы притяжения особенно велики при отрыве и удалении зонда от поверхности, а их дальнодействие достигает величины для Ті и нержавеющей стали соответственно 50 и 100 нм. Кривые отвода имеют сложную форму, как правило, с несколькими ступеньками. В случае поверхности $\alpha-\mathrm{TiO}_{2}$ кривые $\mathrm{ACC}$ (рис. 2e) демонстрируют схожий характер взаимодействия, но величина сил притяжения и их радиус действия несущественно отличаются от таковых для исходной поверхности рутила (рис. 2в).

После 60 с кондиционирования в микроэмульсии дибутилдиксантогена происходит значительное увеличение сил притяжения при подводе к поверхности металлов и оксида титана. Кривые отвода демонстрируют увеличение абсолютной величиныи дальнодействия сил притяжения, особенно для поверхности стали. В случае поверхности $\mathrm{TiO}_{2}$ происходит незначительное увеличение абсолютной величины сил притяжения при практически неизменном их дальнодействии.

\section{Обсуждение}

Изменения силовых кривых подвода и, еще в большей степени, кривых отвода, возникающие после сорбции изученных ПАВ, могут определяться рядом факторов, включая электро-

$$
-341-
$$



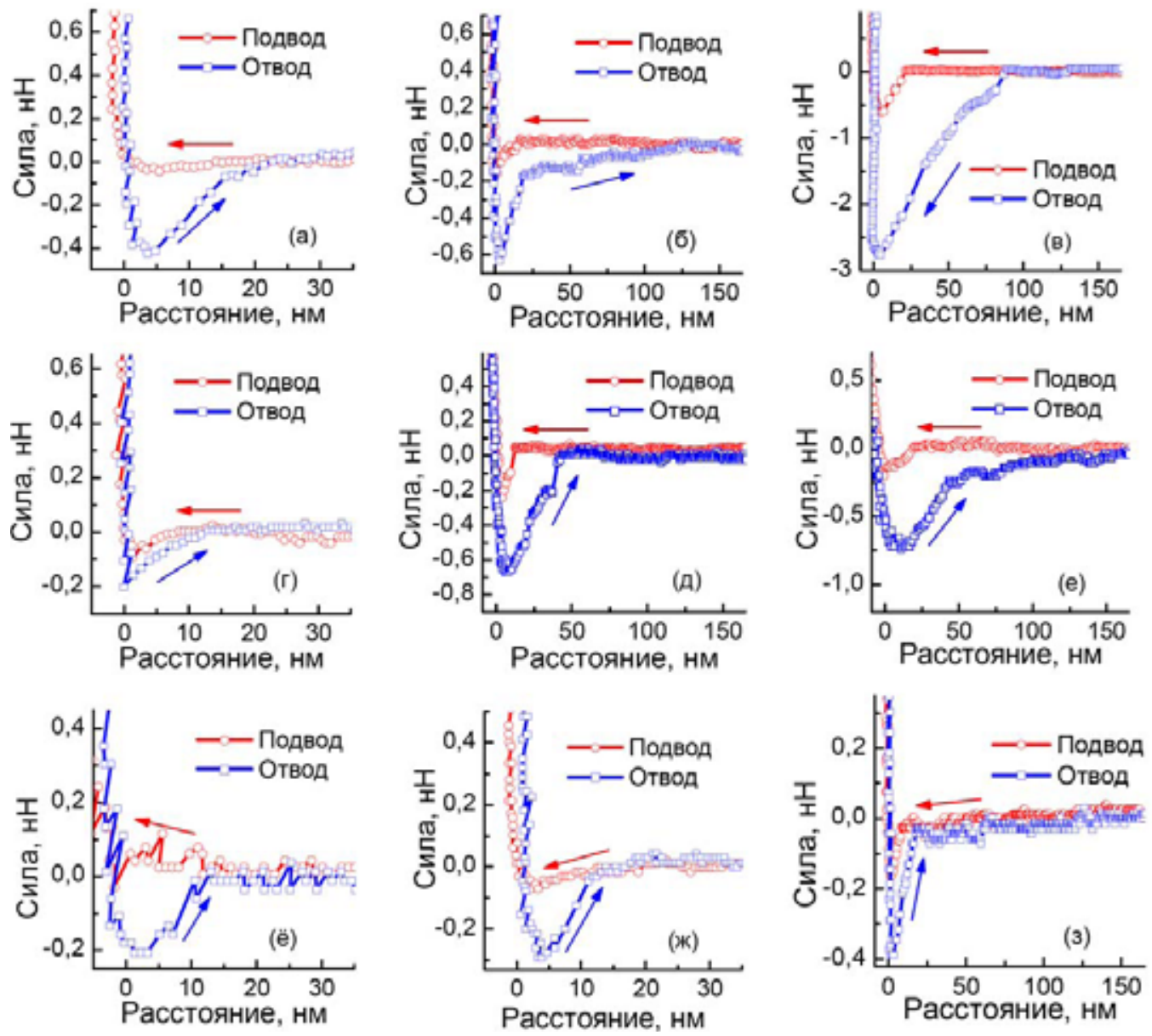

Рис. 2. Типичные атомно-силовые спектры, характеризующие взаимодействие поверхностей нержавеющей стали (а-в), Ті (г-е) и $\alpha-\mathrm{TiO}_{2}$ (ё-з) с острием иглы кантилевера до (а, г, ё) и после обработки раствором 10 мМ н-бутилксантогената калия в течение 10 мин (б, д, ж) либо эмульсией дибутилдиксантогена в течение 1 мин (в, е, и), полученные в жидкости

Fig. 2. Representative AFM force vs separation distance curves between stainless steel (a-в), metallic Ti (ë-3) and $\alpha-\mathrm{TiO}_{2}(\Gamma-\mathrm{e})$, and cantilever tip in deionized water before $(\mathrm{a}, \Gamma, \mathrm{e})$ and after conditioning in $10 \mathrm{mM}$ potassium

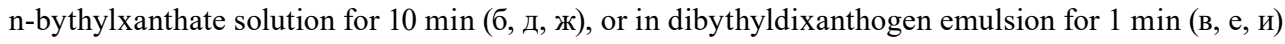

статическое взаимодействие, электрохимическое окисление ксантогенат-ионов с образованием диксантогена, генерацию воздушных нанопузырьков, усиление шероховатости рельефа за счет появления продуктов окисления металлов и/или ксантогенат-ионов и т.д.

Все изученные поверхности в водном растворе до обработки собирателями заряжены отрицательно (изоэлектрическая точка $\mathrm{Ti}=2$ [25], $\mathrm{Fe}=3,2-4$ [26], $\mathrm{TiO}_{2}=6$ [27], тогда как $\mathrm{pH}$ деионизованной воды 5,5 , растворов ксантогената около 7,0). В случае доминирования электростатического вклада в силовые взаимодействия зонд-поверхность, что было бы возможным при благоприятных условиях для хемо- или физической сорбции отрицательно заряженных ксантогенат-ионов, в атомно-силовых спектрах заметно бы росли величины сил адгезии (которые нами оценены глубинами «минимумов»), но не диапазон их действия (вви- 
ду закона Кулона, $\left.\mathrm{F} \sim 1 / \mathrm{r}^{2}\right)$, который, как следует из рис. 2 , при обработке металлических подложек растворами н-бутилксантогената и дибутилдиксантогена увеличивался практически на порядок.

Ранее показано появление нанопузырей на гидрофобных поверхностях [28], в т.ч. нами на поверхностях сульфидных минералов при действии н-бутилксантогената калия [20]. Хотя электрохимический механизм сорбции бутилксантогенат-ионов [29] и образования диксантогена, например, на поверхности пирита [30] рассматривался в основном применительно к флотации сульфидных минералов, не исключено, что сорбция ксантогената из водного раствора, находящегося в контакте с воздухом, на поверхности металлических подложек сопровождается катодной полуреакцией восстановления кислорода (опосредованной, например, в случае нержавеющей стали участием ионов $\mathrm{Fe}^{2+} / \mathrm{Fe}^{3+}$ ) и анодной полуреакцией окисления н-бутилксантогенат-ионов. Нанопузырьки, как нам представляется, могут быть ассоциированы с каплями сорбированного диксантогена, которые либо обеспечивают закрепление тройной межфазной границы «нанопузырек-подложка-вода», либо сами по себе (являясь сильно гидрофобными) служат центрами «нуклеации»нанопузырьков. Мы считаем, что именно нанопузырьки, расположенные и/или образующиеся в месте контакта иглы кантилевера с поверхностью подложки, ответственны за возникновение капиллярных сил, обеспечивающих значительный диапазон адгезионной силы, проявляющейся на кривых отвода АCC [20, 21]. Заметные отличия силовых кривых, полученных на поверхности рутила, от кривых, полученных на металлических поверхностях после обработки н-бутилксантогенатом либо эмульсией диксантогена, могут быть связаны с более низкой реакционной способностью хорошо окристаллизованного слоя $\alpha-\mathrm{TiO}_{2}$ в электрохимическом окислении н-бутилксантогенат-ионов и, как результат, в отсутствие дибутилдиксантогена на поверхности, и ассоциированных с ним нанопузырьков воздуха. Помимо прочего, следует отметить и большую проводимость металлических подложек по сравнению с рутилом [22].

Принимая во внимание отрицательный заряд острия кантилевера, появление и/или увеличение абсолютной величины силы притяжения, наблюдаемое на кривых подвода, может быть объяснено действием электростатической силы; в частности, оно, возможно, связано с инверсией заряда поверхности подложек из-за избирательного притяжения катионов калия, а не н-бутилксантогенат-анионов.

Небольшой рост амплитуды сил притяжения при практически неизменном дальнодействии в случае сорбции дибутилдиксантогена на поверхности $\mathrm{TiO}_{2}$ можно объяснить тем, что диксантоген покрывает ее тонким однородным слоем, либо не изменяя исходную неоднородность поверхности, либо образуя субмикронные капли на поверхности субстрата, увеличивая ее шероховатость. В первом случае будет происходить преимущественное образование нанопузырьков во впадинах (порах), где площадь контакта с гидрофобной поверхностью будет максимальной. Во втором случае нанопузырьки будут располагаться в пространстве между ассоциатами капель дибутилксантогена, которые, как предполагается, могут фиксировать тройную межфазную границу т-ж-г. В любом случае такое расположение нанопузырьков будет уменьшать их способность к деформации и удлинению при отводе иглы кантилевера.

$$
-343-
$$




\section{Заключение}

Измерения величины краевого угла смачивания как меры гидрофобности поверхности показали, что обработка исходных поверхностей исследуемых образцов растворами бутилксантогената калия и эмульсией дибутилдиксантгена приводит к увеличению их гидрофобности. Максимальное увеличение, на $15^{\circ}$, краевого угла смачивания наблюдается на поверхности нержавеющей стали. В случае его оксида $\left(\mathrm{TiO}_{2}\right)$ контакт с эмульсией диксантогена в течение 60 с вызывает, наоборот, небольшое уменьшение краевого угла смачивания, примерно на $3^{\circ}$, видимо, за счет увеличения неоднородности поверхности образца вследствие образования на ней наноразмерных капель и их ассоциатов.

Методом атомно-силовой спектроскопии in situ было показано, что действие ПАВ вызывает увеличение силы притяжения и радиуса ее дальнодействия при подводе иглы кантилевера к поверхности как гидрофобных, так и гидрофильных образцов. Наибольшая величина сил притяжения и их дальнодействия до 150 нм обнаруживается при отводе иглы кантилевера от поверхности образцов. При этом силовые кривые имеют характерный ступенчатый вид, обусловленный образованием на поверхности образцов наноразмерных газовых структур (нанопузырьков), которые и вызывают появление дальнодействующих гидрофобных сил притяжения капиллярной природы. Гидрофобизирующее действие бутилксантогената, как кажется, связано как раз с сорбцией на поверхности образцов дибутилдиксантогена, образующегося в растворе в результате частичного окисления бутилксантогената.

$\mathrm{B}$ случае слабогидрофильной поверхности $\mathrm{TiO}_{2}$ ее контакт с растворами ПАВ вызывает небольшой рост амплитуды сил притяжения при неизменной величине их радиуса дальнодействия, что, по всей видимости, объясняется неоднородностью поверхности образца, препятствующей свободной деформации и удлинению пузырьков, располагающихся преимущественно в углублениях на поверхности.

Таким образом, дибутилдиксантоген проявил себя как высокоактивный реагент, вызывающий образование наноразмерных газовых структур как на гидрофобных, так и на гидрофильных поверхностях.

\section{Благодарности}

Исследование выполнено при финансовой поддержке Российского фонда фундаментальных исследований, в рамках научного проекта № 18-33-00302 мол_а: «Изучение влияния газовых нано- и микроразмерных структур на водо- и льдорепеллентные свойства поверхности».

\section{Список литературы}

1. Israelachvili J.N., Pashley R.M. Measurement of the hydrophobic interaction between two hydrophobic surfaces in aqueous electrolyte solutions. J. Colloid Interface Sci 1984. Vol. 98, P. 500-514.

2. Pashley R., McGuiggan P., Ninham B., Evans D. Attractive forces between uncharged hydrophobic surfaces: direct measurements in aqueous solution. Science 1985. Vol. 229, P. $1088-1089$.

3. Christenson H.K., Claesson P.M. Cavitation and the interaction between macroscopic hydrophobic surfaces. Science 1988. Vol. 239, P. 390-2. 
4. Kurihara K., Kunitake T. Submicron-range attraction between hydrophobic surfaces of monolayer-modified mica in water. J. Am. Chem. Soc. 1992. Vol. 114, P. 10927-10933.

5. Rabinovich Y.I., Yoon R.H. Use of Atomic Force Microscope for the Measurements of Hydrophobic Forces between Silanated Silica Plate and Glass Sphere. Langmuir 1994. Vol. 10, P. 1903-1909.

6. Ishida N., Sakamoto M., Miyahara M., Higashitani K. Attraction between Hydrophobic Surfaces with and without Gas Phase. Langmuir 2000. Vol. 16, P. 5681-5687.

7. Zhang J., Yoon R.-H., Mao M., Ducker W.A. Effects of Degassing and Ionic Strength on AFM Force Measurements in Octadecyltrimethylammonium Chloride Solutions. Langmuir 2005. Vol. 21, P. 5831-5841.

8. Claesson P.M., Blom C.E., Herder P.C., Ninham B.W. Interactions between waterstable hydrophobic Langmuir-Blodgett monolayers on mica. J. Colloid Interface Sci. 1986. Vol. 114, P. 234-242.

9. Eriksson J.C., Ljunggren S., Claesson P.M. A phenomenological theory of long-range hydrophobic attraction forces based on a square-gradient variational approach. J. Chem. Soc., Faraday Trans. 1989. Vol. 85, P. 163-176.

10. Parker J.L., Claesson P.M. Forces between Hydrophobic Silanated Glass Surfaces. Langmuir 1994. Vol. 10, P. 635-639.

11. Attard P. Bridging Bubbles between Hydrophobic Surfaces. Langmuir 1996. Vol. 12, P. 16931695.

12. Christenson H.K., Claesson, P.M. Cavitation and the interaction between macroscopic hydrophobic surfaces. Science 1988. Vol. 239, P. 390-392.

13. Craig V.S.J., Ninham B.W., Pashley R.M. Direct Measurement of Hydrophobic Forces: A Study of Dissolved Gas, Approach Rate, and Neutron Irradiation. Langmuir 1999. Vol. 15, P. 1562-1569.

14. Stevens H., Considine R.F., Drummond C.J., Hayes R. A., Attard P. Effects of Degassing on the Long-Range Attractive Force between Hydrophobic Surfaces in Water. Langmuir 2005. Vol. 21, P. 6399-6405.

15. Ruckenstein E., Churaev N. A possible hydrodynamic origin of the forces of hydrophobic attraction. J. Colloid Interface Sci 1991. Vol. 147, P. 535-538.

16. Attard P. Long-range attraction between hydrophobic surfaces. J. Phys. Chem. 1989. Vol. 93, P. 6441-6444.

17. Podgornik R. Electrostatic correlation forces between surfaces with surface specific ionic interactions. J. Chem. Phys. 1989. Vol. 91, P. 5840-5849.

18. Ishida N., Inoue T., Miyahara M., Higashitani K. Nano Bubbles on a Hydrophobic Surface in Water Observed by Tapping-Mode Atomic Force Microscopy. Langmuir 2000. Vol. 16, P. 6377-6380.

19. Lou S.-T., Ouyang Z.-Q., Zhang Y., Li X.-J., Hu J., Li M.-Q., Yang F.-J. Nanobubbles on solid surface imaged by atomic force microscopy. J. Vac. Sci. Technol., B: Microelectron. Process. Phenom. 2000. Vol. 18, P. 2573-2575.

20. Mikhlin Y.L., Karacharov A.A., Likhatskii M.N. Effect of Adsorption of Butyl Xanthate on Galena, PbS, and HOPG Surfaces as Studied by Atomic Force Microscopy and Spectroscopy and XPS. Int. J. Miner. Proc., 2015. Vol. 144, P. 81-89. 
21. Karacharov A.A., Likhatskii M.N., MikhlinYu.L. Water Emulsions of DibutylDixantogen and Their Interaction with the Surface of Highly Oriented Pyrolytic Graphite and Silicon Dioxide. Journal of Mining Science 2016. Vol. 52, No. 1, P. 184-189.

22. Koole R., Liljeroth P., Oosterhout S., Vanmaekelbergh D. Chemisorption Determines the Photovoltage of a Ti/TiO $/$ /Au/Dye Internal Electron Emission Photovoltaic Cell. J. Phys. Chem. B. 2005. Vol. 109, P. 9205-9208.

23. Hutter J.L.,Bechhoefer J. Calibration of atomic-force microscope tips. Rev. Sci. Instrum. 1993. Vol. 64, P. 1868-1873.

24. Yang C., Tartaglinoa U., Persson B.N.J. Nanodroplets on rough hydrophilic and hydrophobic surfaces. The European Physical Journal E. 2008. Vol. 25, P. 139-152.

25. Kallay N., Torbić Z., Golie M., MatijevitE. Determlnatlon of the Isoelectric Polnts of Several Metals by an Adhesion Method. American Chemical Society. 1991. Vol. 95, P. 7028-7032.

26. Lefèvre G., C`erovic' L., Milonjic' S., Fédoroff M., Finne J., Jaubertie A. Determination of isoelectric points of metals and metallic alloys by adhesionof latex particles. Journal of Colloid and Interface Science. 2009. Vol. 337, P. 449-455.

27. Surface Charging and Points of Zero Charge.Surfacectant Science series. Ed.M. Kosmulski CRC Press, Taylor \& Francis Group, 2009. Vol. 145, 1064 p.

28. Alheshibri M., Qian J., Jehannin M., Craig V.S.J. A History of Nanobubbles. Langmuir 2016. Vol. 32, P. 11086-11100.

29. Чантурия В.А., Вигдергауз В.Е. Электрохимия сульфидов: Теория и практика флотации. М.: Наука, 1993. 206 с. [Chanturiya V.A., Vigdergauz V.E. Electrochemistry of Sulfides. Theory and Practice of Flotation. Moscow, Science, 1993. 305 p. (In Russ.)].

30. Mikhlin Yu., Karacharov A., Tomashevich Ye., Shchukarev A. Cryogenic XPS study of fast-frozen sulfide minerals: flotation-related adsorption of n-butyl xanthate and beyond. J. Electron Spectrosc. Rel. Phenom. 2016. Vol. 206, P. 65-73. 